\title{
Fluorometric Determination of Inorganic Selenium(IV), Selenium(VI) and Organic Selenium in Natural Waters
}

\author{
Yuzuru Nakaguchi*, Keizo Hiraki*, Yuzo Tamari**, Yuzo Fukunaga*, \\ Yasuharu NishiKaWA* and Tsunenobu Shigematsu* \\ *Department of Chemistry, Faculty of Science and Technology, Kinki University, \\ Kowakae, Higashiosaka 577 \\ **Department of Chemistry, Faculty of Science, Konan University, Okamoto, Higashinada-ku, Kobe 6

\begin{abstract}
A method for the simultaneous determination of selenium species such as selenium(IV), selenium(VI) and organic selenium in natural waters has been developed in this paper. Selenium(IV) was fluorometrically determined after extracting the complex of 2,3-diaminonaphthalene (DAN) into cyclohexane. Selenium(VI) in the sample was first reduced to the quadrivalent state by adding potassium bromide in $1.3 \mathrm{M}$ hydrochloric acid solution, then the total inorganic selenium was determined by the same technique as the determination of selenium(IV). The amounts of selenium(VI) can be calculated by subtracting the amounts of selenium(IV) from the total inorganic selenium. Organic selenium was determined as follows: all selenium, including inorganic selenium(IV), selenium(VI), and organic selenium, was coprecipitated with tellurium(IV), and then reduced to elemental selenium and tellurium by hydrazine sulphate in acid solution $(4 \mathrm{M} \mathrm{HCl}$ for river water samples; $1-2 \mathrm{M} \mathrm{HCl}$ for sea water samples). The elemental selenium and tellurium were dissolved in a mixture of nitric acid and hydrochloric acid, reduced to selenium(IV) by boiling with $6 \mathrm{M}$ hydrochloric acid, and also determined by the DAN fluorometry. The amount of organic selenium was estimated by substracting the amount of both selenium(IV) and selenium(VI) from the total amount of selenium determined by this coprecipitation method. Interesting results were obtained from applying this method to river- and sea-water samples.
\end{abstract}

Keywords Speciation, selenium, 2,3-diaminonaphthalene fluorometry, natural waters

Analytical studies on trace amounts of selenium in natural waters, e.g., sea water or river water, have been reported.' Although the details of the distribution of selenium in natural waters have been investigated, simultaneous determination of selenium species in them has not been carried out. Selenium has been recognized as a trace essential element as, and closely related to organisms ${ }^{2-3}, e . g$., it has been indicated that the reaction between inorganic selenium and organic selenium is due to microorganism's action ${ }^{4-5}$. Accordingly it is considered that selenium species such as selenide $\left(\mathrm{Se}^{2-}\right)$, elemental selenium $\left(\mathrm{Se}^{0}\right)$, selenite $\left(\mathrm{Se}^{4+}\right)$, selenate $\left(\mathrm{Se}^{6+}\right)$, and organic selenium exist in natural water, and that the chemical states of these species may vary with the redox potential of water. Although some selenium exists as selenide or elemental selenium under considerably reductive conditions, these species will be released into the atomosphere and the hydrosphere as stable species of elemental selenium or selenium dioxide by burning fossil fuels. ${ }^{1}$ Little elemental selenium will exist in water phase, since this chemical species is fixed in a stable solid phase. In natural waters, therefore, the existence of selenium(IV), selenium(VI) and organic selenium can be indicated.
These selenium species in natural waters can be analyzed by establishing a different determination method for each selenium species.

The determination of selenium in natural waters has been carried out by measuring its complex with diamine using a spectrophotometer ${ }^{6}$, a fluorometer ${ }^{7}$, and a gas chromatograph. ${ }^{8}$ The fluorometric analysis is the most highly sensitive method for the determination of nano gram amounts of selenium; the detection limit is ca. $0.5 \mathrm{ng}$ of selenium in $10 \mathrm{ml}$ of cyclohexane.9 It has been reported that the concentration of selenium in natural waters is in the range of $0.02-400 \mu \mathrm{g} / 1$, and is generally $0.02-0.4 \mu \mathrm{g} / 1$ except in polluted water. In this paper, a method for the simultaneous determination of selenium species such as inorganic selenium(IV) and organic selenium in natural waters has been established and applied to the Japanese river- and sea-waters.

\section{Experimental}

\section{Reagents and apparatus}

High-purity water, obtained by double distillation, 
was used throughout the present study.

A selenite stock solution $(1000 \mathrm{mg} / \mathrm{l})$ was prepared as follows: A 0.1-g portion of high purity elemental selenium (99.999\%) was dissolved into $2 \mathrm{ml}$ of concentrated nitric acid and $0.5 \mathrm{ml}$ of $70 \%$ perchloric acid solutions, and then concentrated until the white fumes of the perchloric acid appeared. All selenium in the solution was reduced to selenite by boiling for 3 min after the addition of $20 \mathrm{ml}$ of $6 \mathrm{M}$ hydrochloric acid solution. The volume of the selenite solution was made up to $100 \mathrm{ml}$ with water.

A selenate stock solution $(1000 \mathrm{mg} / \mathrm{l})$ was also prepared by dissolving the $0.1 \mathrm{~g}$ of high-purity elemental selenium in $4 \mathrm{ml}$ of concentrated nitric acid; the solution was diluted to $100 \mathrm{ml}$ with water.

A DAN solution $(0.1 \% \mathrm{w} / \mathrm{v})$ was prepared as follows: A reagent of DAN (2;3-diaminonaphthalene) produced by Dojin-yakukagaku Co. Ltd. was purified by recrystallization. ${ }^{7}$ A $0.1 \mathrm{~g}$ portion of the dry purified DAN reagent was dissolved with $100 \mathrm{ml}$ of the hot solution $\left(\mathrm{ca} .50^{\circ} \mathrm{C}\right)$ of $0.1 \mathrm{M}$ hydrochloric acid containing $0.5 \mathrm{~g}$ of hydroxylamine hydrochloride. For the further purification of the DAN solution, the separate fluorescent impurities in the DAN solution, the solution was subjected to an extraction procedure which has been described by the authors. ${ }^{9}$

Cyclohexane, commercially available, was used without further purification.

All other reagents and solutions used were of the highest purity available.

Fluorescence- and $\mathrm{pH}$-measurements were made with a fluorescence spectrometer (Hitachi Ltd., model 204 or model 650 , a $150 \mathrm{~W}$-xenon-lamp) and a pHmeter equipped with a glass electrode (Hitachi-Horiba Ltd., model M-5).

\section{Results and Discussion}

Determination of selenium(IV)

Effect of the volume of aqueous laryer on the extraction of selenium $(I V)$. For the determination of nano gram amounts of selenium(IV) in water samples, 200$500 \mathrm{ml}$ of water sample should be used to extract the trace piazselenol (DAN-selenite complex) into $10 \mathrm{ml}$ of cyclohexane. Table 1 shows the effects of the volume of aqueous layer and of the addition of $0.1 \%$ DAN solution on the extraction of selenium(IV). This table shows that the extraction percentage of selenium decreased on decreasing the volume ratio of organic to aqueous layers, although the quantitative extraction of selenium was obtained by the addition of an adequate amount of the DAN solution. The percent extraction of selenium depends on the reaction time for the formation of the piazselenol, e.g., the extraction percentage of $82.5 \%$ at the reaction time for $20 \mathrm{~min}$ was covered to $94.0 \%$ for $40 \mathrm{~min}$. However, this longtime-warming-procedure can not be recommended because of the high values of reagent blank which occur due to the decomposition of the trace amount of DAN. The experimental results shown in Table 1 allow us to suggest that $50 \mathrm{ml}$ of $0.1 \%$ DAN solution be added to $400-500 \mathrm{ml}$ of a water sample, followed by adding $30-50 \mathrm{ml}$ of cyclohexane to aqueous layer. In this extraction, however, if trace amounts of fluorescent matters, which may be mainly organic compounds, are contained in the sample, a positive error is given for the determination of nano gram amounts of selenium in the same sample. In order to avoid this error, the fluorescent matters extracted to cyclohexane can be perfectly destroyed by back-extracting the piazselenol and other fluorescent matters to concentrated nitric acid solutions, followed by wet-ashing the fluorescent compounds with the concentrated nitric acid and perchloric acid solution.

Recommended procedure for the determination of selenium in natural waters. Selenium(IV) content in natural water was determined by the following procedure. To a $1000-\mathrm{ml}$ beaker, a $400-\mathrm{ml}$ portion of sea- or river-waters filtered with a membrane filter (pore size: $0.3 \mu \mathrm{m}$ ) was transferred, and $50 \mathrm{ml}$ of $0.1 \%$ DAN solution and $5 \mathrm{ml}$ of $0.1 \mathrm{M}$ EDTA-NaF solution were added. The sample solution was adjusted to $\mathrm{pH}$ 1.0 with dilute hydrochloric acid and aqua ammonia

Table 1 Effects of the volume of aqueous layer and the addition of DAN solution on the extraction of selenium(IV)

\begin{tabular}{cccccc}
\hline & & \multicolumn{4}{c}{ Extraction percentage of $\mathrm{Se}(\mathrm{IV})$} \\
\cline { 3 - 6 } $\begin{array}{c}\text { Addition of } \\
\text { 0.1\% DAN soln./ml }\end{array}$ & $\mathrm{Se}(\mathrm{IV})$ added/ng & \multicolumn{4}{c}{$\begin{array}{c}\text { Volume ratio in } \\
\text { org. layer/aq. layer(ml/ml) }\end{array}$} \\
\cline { 3 - 6 } & & $10 / 25$ & $10 / 50$ & $10 / 100$ & $10 / 200$ \\
\hline 2 & 100 & & & 47.0 & \\
5 & 10 & 98.0 & 93.0 & 78.0 & 60.0 \\
5 & 100 & 98.0 & 98.5 & 82.5 & 71.0 \\
10 & 100 & & & 87.0 & \\
15 & 100 & & & 96.2 & 90.0 \\
20 & 100 & & & 90.0 & 97.5 \\
\hline
\end{tabular}


solutions, and was warmed in a water bath at $50^{\circ} \mathrm{C}$ for 25 min. After cooling, the solution was transferred to a separatory funnel, and was shaken with $50 \mathrm{ml}$ of cyclohexane for $5 \mathrm{~min}$. After separating the aqueous layer, ca. $30 \mathrm{ml}$ of concentrated nitric acid was added to the organic layer in the funnel, and the funnel was shaken for $5 \mathrm{~min}$. The selenium back-extracted to the aqueous layer was transferred to a beaker and $2 \mathrm{ml}$ of $70 \%$ perchloric acid was added. The beaker was heated on a hot plate until white fumes appeared. To the beaker, $5 \mathrm{ml}$ of $6 \mathrm{M}$ hydrochloric acid was added, and the mixture was boiled for $3 \mathrm{~min}$ to reduced the sample to selenium(IV). After cooling the beaker, $0.5 \mathrm{ml}$ of 0.1 $M$ EDTA-NaF solution and $5 \mathrm{ml}$ of $0.1 \%$ purified DAN solution were added. The mixture was adjusted pH 1.0 and warmed at $50^{\circ} \mathrm{C}$ for $20 \mathrm{~min}$. After cooling to room temperature with ice water, the solution was transferred to a separatory funnel, $10 \mathrm{ml}$ of cyclohexane were added, and then the mixture was shaken for $5 \mathrm{~min}$. The organic layer was transferred to a centrifugal tube with a stopper, and centrifuged to separate the aqueous layer perfectly. The fluorescent intensity of piazselenol in cyclohexane was measured at $520 \mathrm{~nm}$ under excitation wavelength of $375 \mathrm{~nm}$. The amount of selenium in the sample was determined by the comparison with the intensities of definite amounts of selenium in standard solutions. In the above procedure for the determination of selenium(IV), more than $98.9 \%$ of selenium(IV) was recovered from a 100 $\mathrm{ml}$ portion of artificial sea water containing $50 \mathrm{ng}$ of selenium(IV), while no selenium(VI) was recovered from another sea water sample containing $50 \mathrm{ng}$ of selenium(VI). Table 2 lists one of the analytical results of selenium(IV) in water samples from Lake Biwa and sea water from Osaka Bay.

\section{Determination of selenium(VI).}

Selenium(VI) was determined by DAN fluorometry after reducing selenium(VI) to selenium(IV), since the
DAN reagent selectively reacts with selenium(IV). The reduction potential of $\mathrm{SeO}_{4}{ }^{2-}$ to $\mathrm{SeO}_{3}{ }^{2-}$ is reported to be $1.15 \mathrm{~V}$. This value is almost equal to $1.13 \mathrm{~V}$ of $8 \mathrm{M}$ hydrochloric acid $\left(2 \mathrm{Cl}^{-} \rightleftharpoons \mathrm{Cl}_{2}+2 \mathrm{e}^{-}\right)$and to $1.13 \mathrm{~V}$ of hydrobromic acid $\left(2 \mathrm{Br}^{-} \rightleftharpoons \mathrm{Br}_{2}+2 \mathrm{e}^{-}\right)$. Although both chloride and bromide ions are effective for the reduction of selenium(VI), the application of bromide is more useful than chloride for this reduction, because the addition of potassium bromide increase with water volume of the sample. If any other reducing agents than potassium iodide or hydrogen sulfide were used for the reduction, all selenium was reduced to elemental selenium. Accordingly, potassium bromide

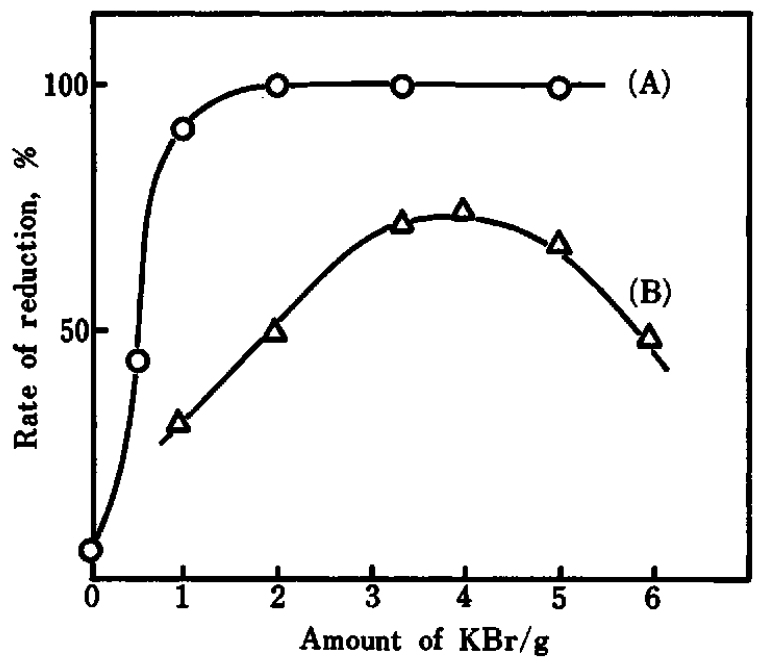

Fig. 1 Effect of addition of potassium bromide on the reduction of selenium (VI) to selenium (IV). Se (VI) added, $100 \mathrm{ng}$; solution, $50 \mathrm{ml}$ of $1.3 \mathrm{M} \mathrm{HCl}$; reaction time, $30 \mathrm{~min}$; (A) a reaction flask with a reflux condenser (B) a reaction flask without a reflux condenser.

Table 2 Determination of selenium(IV) in natural waters by the proposed method

\begin{tabular}{|c|c|c|c|c|c|}
\hline \multirow{2}{*}{ Sample } & \multirow{2}{*}{ Sample taken $/ \mathrm{ml}$} & \multirow{2}{*}{$\mathrm{Se}$ (IV) added/ng } & \multicolumn{2}{|c|}{$\operatorname{Se}(I V)$ found } & \multirow{2}{*}{ Subtracted value $/ \mathrm{ng}$} \\
\hline & & & Net R.F.I. & ng & \\
\hline $\begin{array}{l}\text { Standard } \\
\text { solution }\end{array}$ & & $\begin{array}{c}0 \\
30.0\end{array}$ & $\begin{array}{r}5.0 \\
68.5\end{array}$ & & \\
\hline Lake waterb & $\begin{array}{l}600 \\
600 \\
600 \\
600\end{array}$ & $\begin{array}{c}0 \\
10.0 \\
20.0 \\
30.0\end{array}$ & $\begin{array}{l}12.0 \\
33.7 \\
55.2 \\
74.5\end{array}$ & $\begin{array}{r}5.7 \\
15.9 \\
26.1 \\
35.2\end{array}$ & $\begin{array}{l}5.7 \\
5.9 \\
6.1 \\
5.2\end{array}$ \\
\hline Sea waterc & $\begin{array}{l}400 \\
400 \\
400 \\
400\end{array}$ & $\begin{array}{c}0 \\
10.0 \\
20.0 \\
30.0\end{array}$ & $\begin{array}{l}11.0 \\
31.8 \\
54.0 \\
74.5\end{array}$ & $\begin{array}{r}5.2 \\
15.0 \\
25.5 \\
35.2\end{array}$ & $\begin{array}{l}5.2 \\
5.0 \\
5.5 \\
5.2\end{array}$ \\
\hline
\end{tabular}

a. This volume was calculated by subtracting the added selenium from the found selenium.

b. Collected from Lake Biwa, Nango, Hamaohtsu, Japan.

c. Collected from Osaka Bay, Sukematsu, Izumiohtsu, Japan. 
is recommended as a good reducing agent to reduce selenium(VI) to selenium(IV).

\section{Reduction of selenium(VI) to selenium(IV) by potassium bromide}

Effect of the addition of potassium bromide. Into an Erlenmeyer flask, $50 \mathrm{ml}$ of $1.3 \mathrm{M}$ hydrochloric acid solution, $100 \mathrm{ng}$ of selenium(VI), and a definite amount of potassium bromide were added. The flask was warmed in a boiling water bath for $25 \mathrm{~min}$. Selenium(IV) reduced by this reaction was analyzed by DAN fluorometry. Figure 1 shows the results of this experiments. It was found that some amounts of selenium evaporated from the flask without a condenser during the reductive reaction (see the curve $B$ in Fig. 1). When the reaction was carried out using the flask with a reflux condenser attached, about $100 \%$ of selenium(VI) was not only reduced to selenium(IV), but also recovered under the conditions of the addition of more than $2 \mathrm{~g}$ of potassium bromide (see curve $\mathrm{A}$ in Fig. 1).

Effect of the concentration of hydrochloric acid solution. Figure 2 shows the effect of the concentration of hydrochloric acid solution on the reduction of selenium(VI) under the same conditions as above: curve $A$ is for using a flask with a reflux condenser and curve $B$ is for using a flask without the condenser. Figure 2 shows that selenium(VI) was quantitatively reduced and recovered at concentrations of higher than $1 \mathrm{M}$ hydrochloric acid solution in the case of using the flask with a reflux condenser. However, the reduction

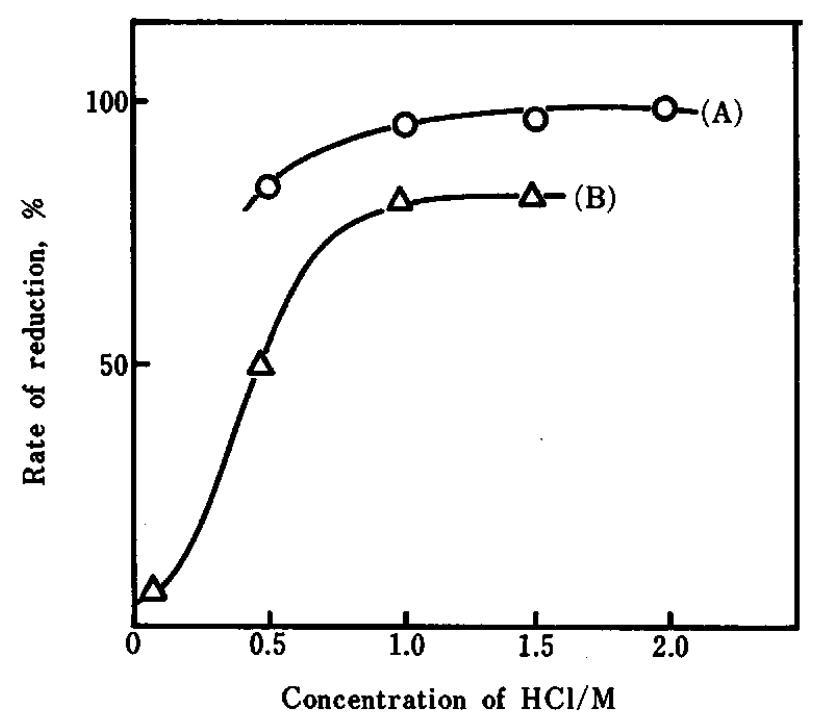

Fig. 2 Effect of the concentration of hydrochloric acid solution on the reduction of selenium (VI) to selenium (IV) by potassium bromide. Se (IV) added, 100 $\mathrm{ng} ; \mathrm{KBr}$ added, $3.6 \mathrm{~g}$; $\mathrm{HCl}$ solution, $50 \mathrm{ml}$; reaction time, $30 \mathrm{~min}$; (A) a reaction flask with a reflux condenser; (B) a reaction flask without a reflux condenser. of selenium under the high concentration of hydrochloric acid is not recommended because of the volatilization of selenium as selenium chloride. Therefore, the concentration of $1.3 \mathrm{M}$ hydrochloric acid was kept during all the procedures in the reduction of selenium(VI).

Effects of the reaction temperature and time. Experiments were carried out by the method described

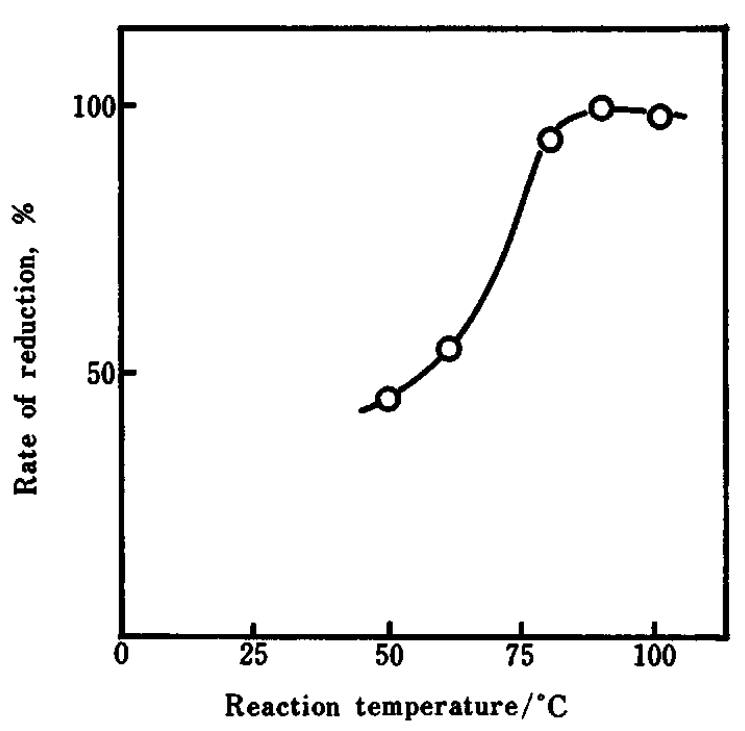

Fig. 3 Effect of the reaction temperature on the reduction of selenium (VI) to selenium (IV) by potassium bromide. Se (VI) added, $100 \mathrm{ng}$; solution, $50 \mathrm{ml}$ of $1.3 \mathrm{M} \mathrm{HCl}$; $\mathrm{KBr}$ added, $2 \mathrm{~g}$; reaction time, $30 \mathrm{~min}$.

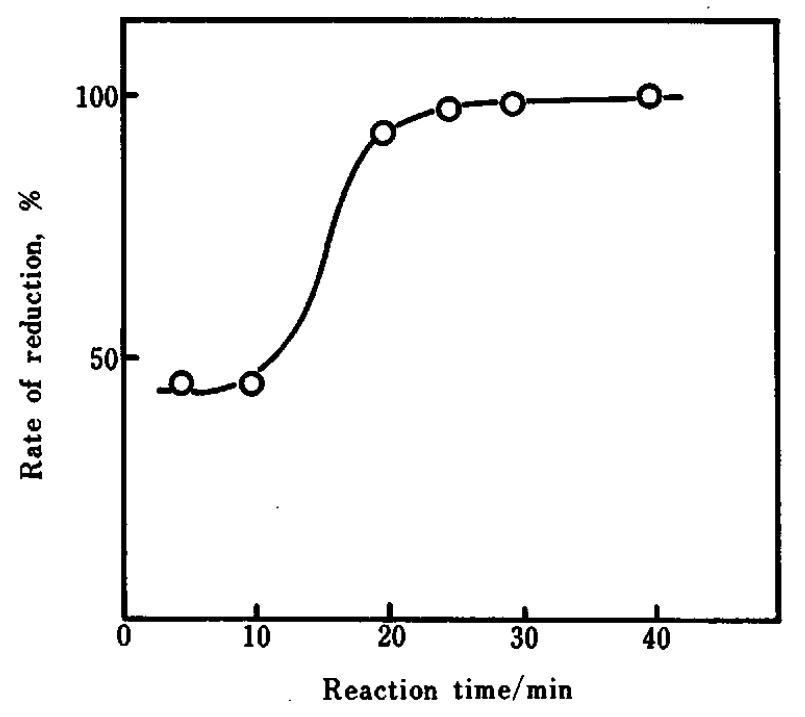

Fig. 4 Effect of the reaction time on the reduction of selenium (VI) to selenium (IV) by potassium bromide. Se (VI) added, $100 \mathrm{ng}$; solution, $50 \mathrm{ml}$ of $1.3 \mathrm{M} \mathrm{HCl}$; $\mathrm{KBr}$ added, $2 \mathrm{~g}$; reaction temp. $90^{\circ} \mathrm{C}$. 
above, i.e., in addition of $100 \mathrm{ng}$ of selenium(VI) and 2 $\mathrm{g}$ of potassium bromide in $1.3 \mathrm{M}$ hydrochloric acid solution. Figures 3 and 4 show the effects of the reaction temperature and time on the reduction of selenium(VI), respectively. As can be seen in these figures, the condition of the reaction at $90^{\circ} \mathrm{C}$ for 25 min was most satisfactory. To heat the flask directly with a burner must be avoided, even if a reflux condenser was attached to the flask, because the volatilization of selenium from the condenser would occur.

Recommended procedure for the determination of selenium $(V I)$ in natural waters. A $200-400 \mathrm{ml}$ portion of a water sample was placed into an Erlenmeyer flask, and the acidity of the solution was adjusted to $\mathrm{pH} 1.0$ by adding the hydrochloric acid solution. After 7-14 $\mathrm{g}$ of potassium bromide were added, the flask was warmed at $90-100^{\circ} \mathrm{C}$ for $25 \mathrm{~min}$ in a water bath. After cooling, $20-40 \mathrm{ml}$ of $0.1 \%$ DAN solution and 4-8 $\mathrm{ml}$ of $0.1 \mathrm{M}$ EDTA-NaF solution were added to the flask. The solution was adjusted to pH 1.0 , warmed at $50^{\circ} \mathrm{C}$ for $15 \mathrm{~min}$, cooled to room temperature, and then transferred to a separatory funnel. To the funnel, $40-80 \mathrm{ml}$ of cyclohexane was added, followed by shaking for $5 \mathrm{~min}$. The selenium in

Table 3 Recovery of selenium(IV) and selenium(VI) by the reduction procedure with potassium bromidea

\begin{tabular}{ccccc}
\hline $\begin{array}{c}\text { Artificial } \\
\text { sea } \\
\text { water/ml }\end{array}$ & \multicolumn{2}{c}{ Se added/ng } & Se found/ & $\begin{array}{c}\text { Recovery } \\
\text { of Se, \% }\end{array}$ \\
\cline { 2 - 3 } Se(IV) & Se(VI) & ng & 96 \\
200 & 0 & 10 & 9.6 & 96 \\
200 & 0 & 50 & 45.0 & 90 \\
200 & 50 & 0 & 47.0 & 94 \\
200 & 0 & 100 & 98.0 & 98 \\
200 & 100 & 0 & 96.0 & 96 \\
200 & 500 & 500 & 1000 & 100 \\
\hline
\end{tabular}

a. $14.4 \mathrm{~g}$ of potassium bromide was added to the sample. the organic layer was back-extracted with $20-40 \mathrm{ml}$ of concentrated nitric acid solution by shaking for $5 \mathrm{~min}$. The nitric acid solution was transferred to a beaker, 1-2 $\mathrm{ml}$ of $70 \%$ perchloric acid solution was added, and the solution was evaporated until the white fumes appeared. To the beaker, 2-5 $\mathrm{ml}$ of $6 \mathrm{M}$ hydrochloric acid solution was added. Then the mixture was boiled for $3 \mathrm{~min}$ (in this procedure, the beaker must be covered with a watch glass). After cooling, the amount of selenium contained in the solution was determined by the DAN fluorometry.

Table 3 shows the results of recovery experiments by this reduction procedure using a $200-\mathrm{ml}$ portion of artificial sea water. The amount of selenium(VI) was determined by subtracting the amount of selenium(IV) (analyzed by the method described above) from the sum of selenium(IV) and (VI), which was obtained by this reduction method. Effects of the coexisting organic selenium compounds on the analysis of selenium(VI) by this reduction procedure with potassium bromide were examined by using diphenyldiselenide (500 $\mathrm{ng}$ as selenium) and gray metallic selenium (500 ng-1 mg). There was no interference of these materials on the recovery results of selenium(IV) and selenium(VI).

Table 4 lists some of the analytical results of selenium(IV) and selenium(VI) in river- and seawaters.

\section{Estimation of organic selenium}

The amount of organic selenium was estimated by subtracting the amounts of both selenium(IV) and(VI) from the total amount of selenium, which was determined by the coprecipitation method with telluri$\mathrm{um}^{7}$, followed by DAN fluorometry, as follows.

A 200-500-ml portion of a water sample was acidified with hydrochloric acid: 4-6 $\mathrm{M}$ for land water or 1-2 $\mathrm{M}$ for sea water. After $2-5 \mathrm{ml}$ of $1 \mathrm{mg} / \mathrm{ml}$ tellurium(IV) solution and 7.2-18 $\mathrm{g}$ of hydrazine sulfate were added to the sample, it was boiled until black

Table 4 Determination of inorganic selenium(IV) and selenium(VI)

\begin{tabular}{|c|c|c|c|c|c|c|c|}
\hline \multirow{2}{*}{ Sample } & \multirow{2}{*}{$\begin{array}{c}\text { Sample } \\
\text { taken/ } \\
\text { ml }\end{array}$} & \multicolumn{2}{|c|}{$\operatorname{Se}($ IV) found } & \multicolumn{2}{|c|}{$\operatorname{Se}(I V)+\operatorname{Se}(V I)$ found } & \multicolumn{2}{|c|}{$\operatorname{Se}(\mathbf{V I})$ found } \\
\hline & & ng & $\mathrm{ng} / \mathrm{l}$ & $\mathrm{ng}$ & $\mathrm{ng} / \mathrm{l}$ & ng & $\mathbf{n g} / \mathbf{1}$ \\
\hline River water b & $\begin{array}{l}600 \\
600 \\
400 \\
400\end{array}$ & $\begin{array}{l}4.4 \\
4.6\end{array}$ & $\begin{array}{l}7.4 \\
7.7\end{array}$ & $\begin{array}{l}6.4 \\
6.4\end{array}$ & $\begin{array}{l}15.9 \\
15.9\end{array}$ & $\begin{array}{l}3.4 \\
3.3\end{array}$ & $\begin{array}{l}8.5 \\
8.2\end{array}$ \\
\hline Sea waterc & $\begin{array}{l}500 \\
500 \\
250 \\
250\end{array}$ & $\begin{array}{l}5.8 \\
6.1\end{array}$ & $\begin{array}{l}11.7 \\
12.2\end{array}$ & $\begin{array}{l}8.1 \\
7.8\end{array}$ & $\begin{array}{l}32.4 \\
31.2\end{array}$ & $\begin{array}{l}5.2 \\
4.8\end{array}$ & $\begin{array}{l}20.7 \\
19.0\end{array}$ \\
\hline
\end{tabular}

a. Selenium(VI) was obtained by subtracting the amounts of $\mathrm{Se}(\mathrm{IV})$ from the amounts of

$\mathrm{Se}(\mathrm{IV})+\mathrm{Se}(\mathrm{VI})$.

b. Collected from the Yamato River, Kashiwara, Osaka, Japan.

c. Collected from Osaka Bay, Sukematsu, Izumiohtsu, Japan. 
Table 5 Analytical results of selenium(IV), selenium(VI) and organic selenium in natural water

\begin{tabular}{lcccc}
\hline \multirow{2}{*}{ Sample } & $\begin{array}{c}\mathrm{Se} \\
\text { added/ } \\
\text { ng }\end{array}$ & \multicolumn{2}{c}{ Analytical values/(ng/l) } \\
\cline { 3 - 5 } River water & 0 & 10.2 & & \\
(Yamato river) & 4 & 15.0 & & \\
& 0 & & 2.5 & \\
& 25 & & 26.8 & \\
& 0 & & & 4.4 \\
& 50 & & & 57.2 \\
Sea water & 0 & 11.7 & & \\
(Osaka Bay) & 20 & 32.2 & & \\
& 0 & & 20.7 & \\
& 20 & & 39.8 & \\
& 0 & & & 19.6 \\
& 50 & & & 75.5 \\
\hline
\end{tabular}

precipitated materials appeared. After cooling, the precipitated elemental tellurium and selenium were filtered with a membrane filter (pore size: $3.0 \mu \mathrm{m}$ ). The precipitate with filter was dissolved with nitric acid solution, and evaporated almost to dryness after the addition of 2-3 ml of $70 \%$ perchloric acid solution. Selenium in the solution was reduced to selenium(IV) by boiling for $3 \mathrm{~min}$ with $5 \mathrm{ml}$ of $6 \mathrm{M}$ hydrochloric acid solution, and determined by DAN fluorometry described above. Organic selenium was decomposed and the selenium was precipitated as elemental selenium. ${ }^{7}$

It was found that the recoveries of selenium added as diphenyldiselenide, by this coprecipitation method, ranged from 92 to $99 \%$.

Analytical values of inorganic selenium(IV), selenium$(V I)$, and organic selenium in river-and sea-waters

Table 5 shows one of the analytical results of selenium. Figure 5 gives the vertical distribution of selenium concentration in Lake Biwa.

Financial support from the Ministry of Education, Science and Culture, Japanese Government, and from Kinki University is gratefully acknowledged.

\section{References}

1. H. W. Lakin, "Trace Elements in the Environmentals",

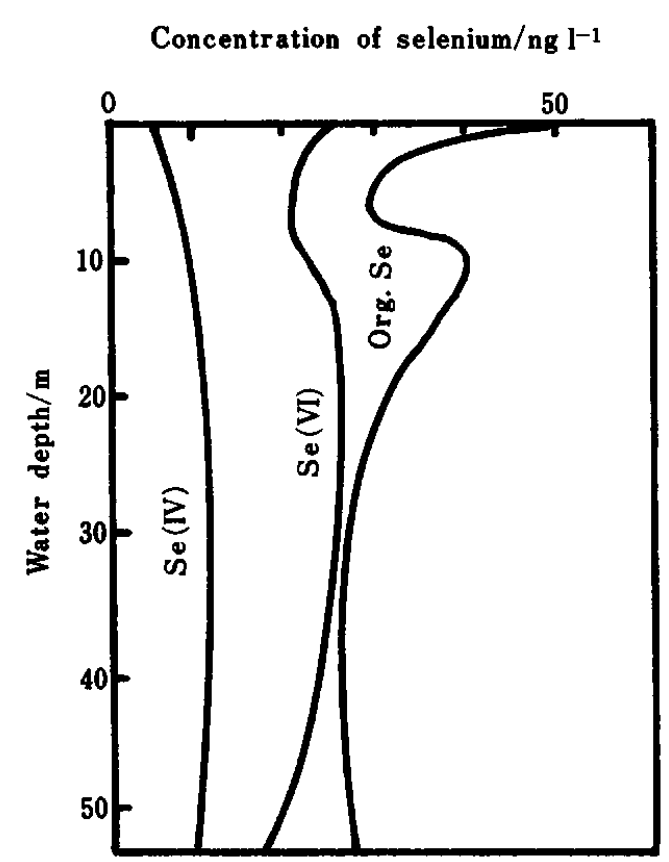

Fig. 5 Vertical distribution of selenium in Lake Biwa.

Advances in Chemistry Series 123, p.96, American Chemical Society (1973).

2. J. J. Dulka and T. H. Risby, Anal. Chem., 48, 640A (1976).

3. W. Mertz, "Ultratrace Metal Analysis in Biological Sciences and Environments", Advances in Chemistry Series 172, p.1, American Chemical Society (1979).

4. U. Förstner and G. T. W. Wittman, "Metal Pollution in the Aquatic Environment", p.265, Springer-Verlag, New York. (1979).

5. H. Hayatsu, "Seitai-noshuku", p.57, Kodansha Co. Ltd., Tokyo - (1975).

6. Y. K. Chau and J. P. Riley, Anal. Chim. Acta, 33, 36 (1965).

7. O. Yoshii, K. Hiraki, Y. Nishikawa and T. Shigematsu, Bunseki Kagaku, 26, 91 (1977).

8. Y. Shimoishi, Anal. Chim. Acta, 64, 465 (1973).

9. Y. Tamari, K. Hiraki and Y. Nishikawa, Bunseki Kagaku, 28, 164 (1979). 